\title{
São os Arranjos Produtivos Locais apoiados capazes de afetar a renda dos municípios do estado do Rio Grande do Sul?
}

\author{
Are the Local Productive Supported Clusters likely to affect the cities of Rio \\ Grande do Sul state income?
}

\section{Arrangements productifs locaux pris en charge sont susceptible d'affecter les revenus des villes de l'état du Rio Grande do Sul?}

\author{
¿Los grupos locales apoyaron que pueda afectar los ingresos de las ciudades en el \\ estado del Rio Grande do Sul? \\ Diogo Sá Carvalho* \\ André Carraro** \\ Pery Francisco Shikida***
}

Recebido em 16/05/2016; revisado e aprovado em 12/06/2016; aceito em 10/09/2016

DOI: http:/ / dx.doi.org/10.20435/1984-042X-2016-v.17-n.4(12)

\begin{abstract}
Resumo: Este artigo avaliou o impacto dos incentivos públicos aos Arranjos Produtivos Locais (APLs) sobre o PIB per capita dos municípios do Rio Grande do Sul. Após a identificação dos APLs, aplicou-se a metodologia de MQO e de Estimação de Diferenças em Diferenças para captar o efeito do apoio ao APL sobre o PIB per capita. Na análise de APLs selecionados, apenas o APL de máquinas e implementos agrícolas apresentou impacto positivo sobre o PIB per capita com significância estatística.
\end{abstract}

Palavras-chave: Arranjos Produtivos Locais; estimação de diferenças em diferenças; Avaliação de Políticas Públicas.

\begin{abstract}
This paper evaluated the public incentives to clusters impact on GDP per capita of cities in Rio Grande do Sul, Brazil, where these clusters were identified. We applied the methodology and OLS Estimation of Differences in Differences to capture the effect of support to clusters on GDP per capita. For specific clusters selected, only the cluster of farm machinery and implements a positive impact on GDP per capita statistically significant.
\end{abstract}

Key words: Clusters; estimation of differences in differences; Evaluation of Public Policies.

Résumé: Ce document a évalué l'impact des incitations publiques à des groupes, sur le PIB par habitant des villes de Rio Grande do Sul, où ces groupes ont été identifiés. Nous avons appliqué la méthodologie et les OLS Estimation des différences de différences pour capturer l'effet de soutien aux clusters sur le PIB par habitant. Pour les clusters spécifiques sélectionnés, seul le cluster de machines agricoles et met en œuvre un impact positif sur le PIB par habitant statistiquement significatives.

Mots-clés: Arrangements Productifs Locaux; differences des differences estimation; Évaluation des Politiques Publiques.

Resumen: En este trabajo se evaluó el impacto de los incentivos públicos a las agrupaciones, en el PIB per cápita de las ciudades de Río Grande do Sul, donde se identificaron estos grupos. Aplicamos la metodología y OLS Estimación de diferencias en diferencias para capturar el efecto del apoyo a grupos en el PIB per cápita. Para grupos específicos seleccionados, sólo el grupo de maquinaria agrícola y pone en práctica un impacto positivo en el PIB per cápita estadísticamente significativas. Palabras clave: Arreglos Productivos Locales; estimación diferencias de las diferencias; Evaluación de Políticas Públicas.

\footnotetext{
* Faculdade de Tecnologia de São Paulo (Fatec Senac), Pelotas, Rio Grande do Sul, Brasil.

** Universidade Federal de Pelotas, Pelotas, Rio Grande do Sul, Brasil.

*** Universidade Estadual do Oeste do Paraná (UNIOESTE), Toledo, Paraná, Brasil.
} 


\section{INTRODUÇÃO}

As duas últimas décadas apresentaram notório crescimento no interesse pelo papel dos Arranjos Produtivos Locais (APLs) na promoção do desenvolvimento regional. O tema passou a frequentar a agenda acadêmica e, por estar associado a uma solução factível para o desenvolvimento econômico, principalmente de regiões relativamente estagnadas economicamente (BOURLEGAT, 2006; COSTA; ANDRADE; SILVA, 2006; KIRSCHBAUM et al., 2007), ganhou espaço também na agenda política (MINISTÉRIO DO DESENVOLVIMENTO, INDÚSTRIA E COMÉRCIO EXTERIOR [MDIC], 2013; SECRETARIA DE DESENVOLVIMENTO E PROMOÇÃO DO INVESTIMENTO DO RIO GRANDE DO SUL [SDPI], 2013).

O APL tem como característica ser uma aglomeração "de agentes econômicos, políticos e sociais, localizados no mesmo território e que operam em atividades produtivas correlacionadas" (RIBEIRO et al., 2013, p. 106). Embora os APLs sejam marcados pela ausência de uma estrutura organizativa e de governança, podem atuar como impulsionadores da economia, transformando alguns empreendimentos em forças motrizes de desenvolvimento local (RIBEIRO et. al., 2013).

A partir do ano 2000, o tema entrou em debate no planejamento econômico por meio da lei do plano plurianual do governo federal (MDIC, 2000). Desde então, governos estaduais e municipais, bem como agências de fomento ao desenvolvimento, passaram a tratar do tema em maior ou menor intensidade. $\mathrm{O}$ governo do Rio Grande do Sul iniciou, em 1999, o Programa de Apoio aos Sistemas Locais de Produção, o qual tinha por objetivo apoiar o desenvolvimento de APLs em torno de cadeias produtivas mais dinâmicas, por meio de incentivos ao investimento, apoio à organização de atividades associadas e ao arranjo de cadeias produtivas (TATSCH; PASSOS, 2008).
De uma forma geral, os estudos sobre APLs no Brasil possuem um viés mais qualitativo. Nessa linha, destacam-se Bourlegat (2006), Costa et al. (2006) e Tatsch e Passos (2008). Embora a abordagem qualitativa seja relevante, é também necessário e importante, tanto em termos acadêmicos como em termos pragmáticos, subsidiar o formulador de políticas públicas com avaliações do impacto econômico que permita ao formulador identificar casos de sucesso ou necessidades de mudanças, de tal forma a obter o resultado esperado quando do desenho do incentivo político.

Esta é a lacuna na literatura nacional que este artigo pretende suprir. Contudo este artigo não tem a pretensão de dar uma resposta definitiva sobre qual é o papel do Arranjo produtivo Local no crescimento econômico, ou se ele passou a ser um indutor do crescimento econômico, mas de apresentar evidências empíricas que possam estimular novos trabalhos de avaliação de impacto econômico em políticas públicas de impacto regional.

Nesse contexto, o objetivo geral deste artigo é analisar o efeito do incentivo público ao fomento de APLs, normatizado a partir do ano 2000 com a inclusão do tema na lei do plano plurianual. Especificamente, pretende-se avaliar o impacto dessa lei sobre a renda per capita nos municípios do Rio Grande do Sul onde há arranjos produtivos locais identificados. Nesse sentido, a questão central deste artigo é: o apoio público ao fomento dos APLs tem efeito sobre o PIB per capita dos municípios do Rio Grande do Sul com arranjos produtivos identificados?

A escolha do Rio Grande do Sul deve-se ao fato dos APLs poderem ser o canal de retomada do crescimento econômico do estado, visto que, nos últimos anos, o Rio Grande do Sul reduziu sua participação no PIB nacional e tem perdido o dinamismo econômico em relação aos demais estados (BANCO CENTRAL DO BRASIL [BCB], 2011). Por conta da 
perda no dinamismo econômico, a busca de novos arranjos industriais foi um dos mecanismos pensados como indutores de um novo processo de crescimento econômico (SDPI, 2013). Sendo uma política relevante para o Rio Grande do Sul, é importante avaliar a sua eficácia em promover esse tipo de arranjo produtivo no estado.

O artigo está estruturado em cinco seções. Além desta introdução que apresenta o objetivo do artigo, a seção seguinte discorre sobre o referencial teórico. A terceira seção traz a estratégia de estimação e a fonte dos dados utilizados. A quarta seção apresenta os resultados e, por fim, na última seção, são tecidas as considerações finais.

\section{A ESTRUTURA DE MERCADO E OS ARRANJOS PRODUTIVOS LOCAIS}

Uma estratégia competitiva de que as empresas de um mesmo setor se utilizam é a aglomeração como forma de obter maior competitividade no mercado. Ao atentar para a estrutura, elas buscam um desempenho econômico melhor via ajuste na conduta de suas ações: o modelo estrutura-conduta-desempenho (ECD) ajuda a entender o comportamento estratégico que está presente na decisão de aglomeração das empresas de um mesmo setor em um arranjo produtivo. A seguir, tal modelo é descrito para, posteriormente, subsidiar uma discussão sobre arranjos produtivos locais a ser apresentada.

\subsection{Modelo estrutura-conduta- desempenho}

O modelo estrutura-conduta-desempenho (ECD) é um paradigma de análise para utilizar o conceito de competitividade empresarial. Para que o conceito possa ser corretamente operacionalizado é necessário que os principais elementos-chave do ambiente interno que irão determinar a estrutura do mercado, a conduta dos empresários e o desempenho estejam incorporados no modelo de análise (SCHERER; ROSS, 1990).

O paradigma ECD estabelece que o desempenho competitivo (rentabilidade) está relacionado com a estrutura de mercado (nível de concentração industrial). A conduta empresarial é o canal que determinará seu melhor ou pior desempenho. Ou seja, por meio do seu comportamento em relação à política de vendas e fixação de preços, bem como à decisão de aliar-se ou não com outros empresários do setor irá interferir na dinâmica de seu crescimento e de sua lucratividade (TIROLE, 1988).

Dentro desse paradigma, aborda-se o conceito de competitividade sistêmica, que é mais consistente que o conceito de competitividade convencional, por ser mais amplo ao não se limitar aos fatores internos da empresa como as economias de escala e escopo. O conceito vai além ao adicionar variáveis externas que influenciam a empresa como a infraestrutura econômica, a infraestrutura social, a política macroeconômica bem como as políticas setoriais e regionais, entre outras como o desenvolvimento de capital humano e as políticas de fomento, geração e difusão de inovações tecnológicas (POSSAS, 1999).

Ao estar atento a toda a cadeia de negócios, à modernização das instituições, o empresário busca a melhor estratégia, a melhor conduta, para preservar a competitividade de sua empresa ao longo do tempo. O objetivo de considerar a abordagem sistêmica é compreender a dinâmica das variáveis macroeconômicas, microeconômicas, institucionais, sociais e políticas, cujo resultado pode ser alcançar vantagens competitivas necessárias para criar, manter e/ou ampliar a participação da empresa no seu mercado (POSSAS, 1999; 2002).

Os fatores sistêmicos que determinam a competitividade em uma economia moderna têm na sua origem, segundo Carvalho et al. (2006), três níveis: fatores 
sistêmicos regulatórios, que estimulam o ambiente competitivo; os fatores infraestruturais, que provêm externalidades positivas capazes de aperfeiçoar a competitividade empresarial; e os fatores sistêmicos político-institucionais, que são as instituições sociais e governamentais que afetarão os planos dos empresários.

O que se observa a partir do paradigma ECD é que os Arranjos Produtivos Locais podem ser representados como uma estratégia empresarial, na qual a aglomeração e cooperação entre os empresários são a conduta que busca, junto aos fatores sistêmicos, um melhor desempenho do setor. A seção seguinte define melhor os APLs e apresenta alguns casos que parecem confirmar essa estratégia.

\subsection{Arranjos Produtivos Locais: estratégia para um melhor desempenho}

Um Arranjo Produtivo Local (APL) é uma aglomeração geográfica de produtores de um bem e/ou serviços onde os agentes pertencentes ao arranjo apresentam um mínimo grau de interação que darão perenidade ao arranjo (BANCO NACIONAL DE DESENVOLVIMENTO ECONÔMICO ESOCIAL [BNDES], 2004). Conceito similar é adotado pelo Serviço Brasileiro de Apoio às Micro e Pequenas Empresas (SEBRAE), que entende que os APLs são aglomerações de empresas localizadas em mesmo território. Essas empresas apresentam especialização produtiva, além de manterem articulação, interação, cooperação e aprendizagem entre si e com outros atores locais em algum grau de intensidade (SEBRAE, 2002).

É justamente o conceito do SEBRAE que embasa os estudos sobre APLs no Brasil. A Fundação de Economia e Estatística do estado do Rio Grande do Sul (FEE) em parceria com a Agência Gaúcha de Desenvolvimento e Promoção do Investimento (AGDI) lançou mão desse conceito para embasar seu trabalho (ZANIN; COSTA; FEIX, 2013). Neste estudo, estão todos os APLs existentes no estado.

A literatura internacional apresenta trabalhos que buscam avaliar o papel do suporte público na promoção dos arranjos produtivos. De acordo com Martin, Mayer e Mayneris (2011), as políticas de formação de cluster tornaram-se populares em muitos países, mas não têm sido avaliadas extensivamente. Falck, Heblich,e Kipar (2010) exploram essa lacuna e procuram avaliar a política de apoio público introduzida na Baviera (Alemanha), utilizando a metodologia diferença-em-diferenças-em-diferenças (Diferenças Triplas ou DDD). A política teve como objetivo estimular a inovação e a competitividade regional. Os resultados mostraram que aumentou a probabilidade de uma inovação por uma empresa no setor e houve diminuição da despesa em P\&D nas indústrias-alvo.

Buscando avaliar a política pública implementada no Projeto Industrial Cluster (ICP) no Japão, Nishimura e Okamuro (2011) utilizam a metodologia de diferenças em diferenças, para avaliar os diferentes impactos existentes entre o apoio direto e o suporte de rede/coordenação indireta. Os resultados sugerem que programas de apoio indireto tem um impacto grande e forte, sobretudo no que diz respeito à inovação, enquanto o apoio direto de P\&D tem um efeito bastante fraco.

Tentando analisar empiricamente uma política pública de promoção de clusters industriais na França, Martin, Mayer e Mayneris (2011) avaliam quantitativamente uma política de clusters explorando dados de empresa, utilizando uma base de dados ampla com informações sobre as empresas e sobre as políticas públicas. A metodologia escolhida também foi a DDD. Os resultados mostram que a política não conseguiu reverter o declínio relativo da produtividade para as empresas visadas e a política também não teve efeito sobre o emprego e as exportações de empresas envolvidas na política. Outra característica 
da literatura internacional é que ela apresenta trabalhos que destacam o papel dos arranjos produtivos lançando mão de variáveis puramente econômicas, como PIB ou taxa de crescimento. Delgado, Porter e Stern (2012) estudaram o papel dos clusters no desempenho econômico regional nos Estados Unidos. Eles utilizaram o salário, a taxa de crescimento dos salários, o crescimento do emprego e a taxa de novas patentes para cada região selecionada.

Os autores encontraram em seus resultados que quanto maior a força do aglomerado industrial, maiores eram os salários não apenas das indústrias selecionadas, mas o salário regional era influenciado pelos altos salários pagos no cluster. A vitalidade e pluralidade das inovações também foram variáveis significativas para determinar o desempenho das regiões.

Ainda segundo Delgado, Porter e Stern (2012), as indústrias que participam de um cluster forte registram maior crescimento do emprego, bem como um maior crescimento dos salários, número de estabelecimentos e patenteamento. Eles também encontram evidências de que novas indústrias regionais emergem onde há um ambiente de cluster forte e sugerem que a presença de fortes clusters em uma região aumenta as oportunidades de crescimento em outras indústrias e clusters.

Em relação à inovação no âmbito dos clusters, Chatterji, Glaeser e Kerr (2013) realizaram uma pesquisa em vários aglomerados industriais nos Estados Unidos procurando descobrir o papel do empreendedor no processo de criação. Os resultados mostram que o empreendedorismo é importante para dinamizar o crescimento econômico de uma região, mas não encontra evidências que aprovem as políticas governamentais que têm a intenção de "criar empreendedores".

Hashino e Otsuka (2013) analisam a pertinência do modelo Sonobe-Otsuka, que procura explicar o processo de desenvolvimento de longo prazo, baseado em cluster nos países em desenvolvimento. Foi avaliado um modelo endógeno de desenvolvimento industrial baseado em Sonobe-Otsuka que seria, segundo os autores, o único modelo concebido a explicar o processo de longo prazo de desenvolvimento de clusters em países em desenvolvimento. Eles concluem que é importante reconhecer o papel das associações comerciais na introdução de novas tecnologias e gestão do conhecimento, e proteger a marca de clusters industriais. Ainda ressaltam que o apoio do governo local para o desenvolvimento de clusters industriais também pode ser importante se o custo de realizar uma ação coletiva voluntária é proibitivo.

Buscando dar uma definição operacional para um APL, Costa (2011) analisa a evolução de todos os conceitos que envolvem o termo e conclui a importância da aglomeração industrial para o desenvolvimento econômico de uma região devido aos ganhos que a sinergia empresarial gera: atração de mão de obra qualificada, inovações tecnológicas, novas empresas para o setor a montante e a jusante, entre outros aspectos. Embora haja discussões conceituais sobre a nomenclatura adequada às aglomerações industriais, como clusters ou Sistemas Locais Produtivos (SLPs), o que não deve mudar é o sentido do objeto de análise (SUZIGAN et.al., 2004).

A política brasileira dispõe de regulamentações específicas para a promoção e desenvolvimento dos APLs, como a inclusão do tema nos planos plurianuais PPA 2004-2007 e 2008-2011 e na criação de um grupo de trabalho permanente - GTP APL (MDIC, 2000). Esse grupo tem o objetivo de articular as ações governamentais dando apoio integrado aos APLs. Além do grupo, cada estado brasileiro possui um núcleo estadual de apoio aos arranjos produtivos locais.

A literatura nacional apresenta uma discussão mais qualitativa sobre a promoção dos arranjos produtivos locais. Noronha e Turchi (2005) exploram a im- 
portância do ambiente institucional nos quais os arranjos produtivos locais estão inseridos. Eles argumentam que padrões formais e informais de contrato, bem como a passagem de um tipo para outro, pode definir o sucesso ou o fracasso de um APL. Amaral Filho (2011) procura associar os sistemas e arranjos produtivos locais ao desenvolvimento local e regional, bem como a inserção de políticas públicas para o crescimento. Adotando uma perspectiva evolucionista, o autor supracitado argumenta que, adotando conceitos desenvolvidos pelos institucionalistas, esse tipo de estratégia de desenvolvimento pode ficar mais robusto, isto do ponto de vista da governança dos agentes do sistema.

Britto e Stallivieri (2010) discutem construção de competências na produção de software no Brasil, a partir do conceito de arranjos produtivos locais e fazendo uso de procedimentos de estatística multivariada para identificar as aglomerações industriais. Eles apontaram que existe uma grande heterogeneidade na construção de competências no setor e sugerem um melhor gerenciamento da estrutura de governança local.

No Brasil, os APLs estão presentes nas mais diversas tipologias produtivas. Boulegart (2006) destaca a capacidade de inovação do APL da fécula da mandioca no sudeste do Mato Grosso do Sul que movimenta a economia do agronegócio do Vale do Ivinhema. Apesar de empresas vindas de outros lugares, os agricultores locais garantem a identidade do APL e este é responsável por quase $90 \%$ da mão de obra empregada nas unidades produtivas agrícolas.

No setor da saúde, tem-se o arranjo produtivo de Equipamentos Médicos, Hospitalares e Odontológicos, APLEMHO de Ribeirão Preto, SP, em funcionamento desde 2008, em um projeto de Ciência e Tecnologia da Fundação Instituto Polo Avançado de Saúde (FIPASE). Esse APL desenvolve projetos para promover inovação constante e de alta tecnologia entre as empresas, com o objetivo de tornar a cidade e região polo de referência no setor de saúde no Brasil (FIPASE, s/d).

Outro APL na área de saúde está localizado em Recife, PE, conhecido como Polo Médico do Recife. A época em que surgiu refletiu um ponto de inflexão na concepção de serviços médicos de saúde no Brasil: transitava-se da medicina generalizada e de 'família' para uma medicina altamente mercantil e especializada, razão pela qual esse arranjo forjou-se e consolidou-se por médicos junto com clínicas, laboratórios e hospitais privados (BNDES, 2004).

No Rio Grande do Sul, a política de apoio aos APLs faz parte da Política Industrial do estado dentro do eixo que promove a política da economia da cooperação (SPDI, 2013). Normativamente, essa política está respaldada pelo Decreto n. 48.936 que regulamenta a Lei n. 13.839, que institui o Programa de Fortalecimento das Cadeias e Arranjos Produtivos Locais.

Entre os APLs existentes no território gaúcho, os casos do setor de Vitivinicultura, de máquinas e implementos agrícolas, metal mecânico e o APL do setor moveleiro são destacados como os mais exitosos (TATSCH; PASSOS, 2008) e são analisados pela literatura. Kirschbaum et al. (2007) estudaram as origens e a evolução do arranjo produtivo da Vitivinicultura. Segundo a autora, o APL do vinho refletindo os hábitos dos seus imigrantes, se fortaleceu ao longo do século $X X$, constituindo vinícolas cooperativas que desenharam inovações que garantiram qualidade ao produto que conquistou mercados no país e fora dele.

Outro exemplo da diversidade de tipologias produtivas que podem ser encontradas em um APL é o arranjo produtivo de máquina e implementos agrícolas localizado no noroeste do Rio Grande do Sul. Tatsch e Passos (2008) elaboraram um detalhado estudo sobre esse arranjo, destacando as instituições envolvidas e como elas são importantes para o fomento 
de inovações para soluções para as demandas da fronteira agrícola.

Lançando mão de um questionário para avaliar a relevância de um APL, Dias (2011) aplicou-os aos dirigentes de uma das principais políticas públicas com vistas ao desenvolvimento territorial brasileiro: a Política Nacional de Desenvolvimento Regional (PNDR) do Ministério da Integração Nacional (MI). Nessa pesquisa, ele concluiu que os arranjos produtivos locais influenciam positivamente o alcance dos objetivos empresariais e se constituem em uma forte ferramenta de suporte, tendo uma importância de destaque entre os fatores que impulsionam o desenvolvimento.

De forma geral, as metodologias utilizadas para avaliar o desenvolvimento desses arranjos produtivos locais estão baseadas no levantamento de informações por meio da aplicação de um questionário aos participantes do arranjo, procurando captar sua percepção acerca da relevância socioeconômica deste para a região onde está inserido, como fazem Dias (2011) e Costa, Andrade e Silva (2006), por exemplo. Uma abordagem complementar é utilizar a perspectiva histórica (vide KIRSCHBAUM et al., 2007) destacando a importância de determinada atividade para o local. Embora sejam abordagens que contribuam para a descrição do processo de implementação e desenvolvimento dos APLs, fica registrada a carência de uma abordagem quantitativa que complemente essa análise ou elucide alguma característica não observada anteriormente.

A estratégia de pesquisa apresentada a seguir busca suprir esse gargalo para os APLs identificados no Rio Grande do Sul (ZANIN; COSTA; FEIX, 2013), procurando observar se a renda per capita média dos municípios nos quais existem pelo menos um APL apoiado apresentou crescimento para os anos observados o qual os difere do desempenho observado pelos demais municípios que não possuem APL.

\section{ESTRATÉGIA EMPÍRICA E DADOS}

Para responder à pergunta central deste artigo, será aplicado o método de dados em painel com estimação de efeitos fixos. A proposta é buscar estimar o efeito da política pública de apoio aos arranjos produtivos locais sobre o PIB per capita nos municípios do Rio Grande do Sul com APLs identificados.

Atualmente no estado gaúcho existem 170 aglomerações industriais. Muitas aglomerações poderiam ser agrupadas em uma única, pois se estendem territorialmente a municípios contíguos. Essas aglomerações abrigam 11.952 estabelecimentos empresariais e empregam 341.370 pessoas (ZANIN; COSTA; FEIX, 2013).

No entanto, conforme BNDES (2004), base de dados neste trabalho, são identificados 41 APLs, dos quais 33 são apoiados e separados por tipologia. Destes, apenas uma pequena parte está documentada como um APL ativo com definição clara e precisa da data de início de formação do APL e com apoio de governança estabelecida a partir do incentivo fornecido pela lei estadual de apoio aos APLs.

A partir desse levantamento de informações, construiu-se a seguinte estratégia de estimação. No primeiro modelo, é estimado o efeito dos 33 APLs apoiados que possuem registro para o ano de 2010 sobre a renda nos municípios. Para o primeiro modelo, foi feita a suposição de que eles já existiam no ano de 2000. Em seguida, como não existe a informação precisa sobre a data de criação e início do apoio sobre a totalidade dos 33 APLs avaliados no primeiro modelo, foram selecionados apenas os APLs cuja existência a literatura registra no ano de 2000. Dos 33 APLs, quatro se enquadram nesse requisito. Os quatro APLs (metalmecânico, vitivinicultura, moveleiro e máquinas e implementos agrícolas) são os APLs mais tradicionais e consolidados sendo, potencialmente, os mais aptos a captar o efeito da política de incentivo do governo. 
Para buscar variação no tempo, são considerados dois períodos de tempo prévios à existência da política de apoio: 1980 e 1996. As observações referentes aos dois anos são consideradas observações pré-tratamento. A partir do ano de 2000, os APLs passam a receber o apoio do governo estadual e federal e passam a ser considerados tratados. Assim a estrutura dos dados utilizados neste artigo é de um painel de dados no qual os indivíduos (no caso municípios) são acompanhados nos anos de 1980, 1996, 2000, 2007 e 2010. A definição desses anos se deu pela disponibilidade de informações de PIB e população municipal.

O problema mais frequente quando da utilização de dados em painel é a presença de heterogeneidade não observada. A hipótese aqui é que podem existir fatores que determinam a variável dependente, mas, por não serem observáveis ou mensuráveis, não estão sendo considerados na equação dentro do vetor de variáveis explicativas.

Este modelo por ser representado por:

$y_{i t}=x_{i t} \beta+c_{i}+\varepsilon_{i t}$, onde $i=1,2, \ldots, n ; t=1,2, \ldots ., T$

Em que $c_{i}$ representa a heterogeneidade não observada em cada unidade de observação (no caso, municípios) que são constantes ao longo do tempo.
Segundo Wooldridge (2006), se c for correlacionado com qualquer variável no vetor de $\mathrm{x}_{\mathrm{it}}$ então, ao aplicar-se o método de $\mathrm{MQO}$, as estimativas serão não apenas enviesadas como também inconsistentes. Nesse caso, para estimar a equação de forma consistente, é adotado o método de dados de painel com efeitos fixos.

Contudo o que se está desejando é avaliar o efeito da política do governo em apoiar um APL sobre a renda per capita do município. Para analisar o efeito dessa política, foi utilizada a metodologia de diferenças-em-diferenças (WOOLDRIDGE, 2006). O que se faz aqui é dividir a amostra de municípios em dois grupos: o grupo dos municípios que não possuem APLs apoiados (chamado de grupo de controle) e o grupo dos municípios que possuem APL apoiado (chamado de grupo de tratamento). Para ambos os grupos, precisou-se da informação de renda per capita antes e depois do início da existência de um APL apoiado. Se os grupos forem iguais em tudo o mais e apenas diferentes pelo fato de um grupo ter recebido o apoio de um APL, então, se houver diferença na taxa de crescimento, esse efeito é causado pela política de apoio ao APL. Caso contrário, ambos os grupos seguem com a mesma trajetória de crescimento da renda per capita. $\mathrm{O}$ quadro 1 esquematiza esse procedimento.

\begin{tabular}{|c|c|c|c|}
\hline & Antes & Depois & Diferenças \\
\hline Controle & A & B & A-B \\
\hline Tratamento & C & D & C-D \\
\hline Diferenças & A-C & B-D & (C-D)-(A-B) \\
\hline
\end{tabular}

Quadro 1 - Representação do procedimento de Diferença-em-Diferença

Fonte: Elaborado pelos autores

Como o fato de um município ter ou não ter um APL apoiado em sua região geográfica não é um evento aleatório, o modelo de efeito fixo captura as características não observáveis dos municípios que podem explicar o fato do município ter ou não um APL apoiado (questões de capital social, estrutura política, organi- zação produtiva já existente etc.) que são fixas no tempo.

Os dados sobre cada município referente ao PIB e à população foram obtidos junto ao Instituto Brasileiro de Geografia e Estatística (IBGE). O mapeamento dos APLs no estado foi obtido junto ao Banco Nacional de Desenvolvimento Econômico 
e Social (BNDES), através do Projeto Análise do Mapeamento e das Políticas para Arranjos Produtivos Locais no Sul, Sudeste e Centro-Oeste do Brasil (BNDES, 2004): Os Arranjos Produtivos Locais no Rio Grande do Sul - Mapeamento, Metodologia de Identificação e Critérios de Seleção para Políticas de Apoio. A tabela 1 exibe as estatísticas descritivas das variáveis utilizadas.

Tabela 1 - Estatísticas descritivas das variáveis utilizadas

\begin{tabular}{ccccccc}
\hline Ano & Variável & Obs & Mean & Std. Dev. & Min & Max \\
1980 & Pibpc & 232 & 5,646086 & 2,742307 & 1,978729 & 20,59049 \\
& Apl & 497 & 0 & 0 & 0 & 0 \\
1996 & Pibpc & 427 & 5,437333 & 4,595591 & 1,819028 & 66,37299 \\
\hline & Apl & 497 & 0 & 0 & 0 & 0 \\
2000 & pibpc & 467 & 6,11375 & 5,631491 & 2,309942 & 113,8255 \\
& Apl & 497 & 0,7605634 & 0,4271696 & 0 & 1 \\
2007 & pibpc & 496 & 8,066066 & 5,718456 & 2,5532 & 110,028 \\
& Apl & 497 & 0,7605634 & 0,4271696 & 0 & 1 \\
2010 & pibpc & 496 & 8,766298 & 5,579958 & 3,13249 & 99,95057 \\
& Apl & 497 & 0,7605634 & 0,4271696 & 0 & 1 \\
\hline
\end{tabular}

Em que:

Pibpc = variável para o valor do PIB per capita a preços constantes de 2000

$\mathrm{Apl}=$ variável dummy que identifica se o município possui APL apoiado

O apoio aos APLs como política pública tem seu marco institucional legal com a inclusão do tema na lei do plano plurianual a partir do ano 2000. Desde então, os órgãos de fomentos, associações de classe, governos nas três esferas passaram a incluir o tema APL nas suas agendas de desenvolvimento.

O modelo a ser estimadoé o seguinte:

$$
\ln y_{i t}=\theta_{i}+\lambda_{t}+\beta A P L_{i t} * d+\epsilon_{i t}
$$

Em que:

$\ln y_{i t}=$ logaritmo do PIB per capita

$\theta_{i}=$ efeito fixo dos municípios

$\lambda_{t}=$ tendência

$\beta A P L_{i t} d=$ = variável dummy para identificar quando existe política de apoio.

$\mathrm{d}=0$, quando não há APL apoiado

$\mathrm{d}=1$, quando há APL apoiado

$\epsilon_{i t}=$ termo estocástico de erro
Inicialmente foi estimado um modelo de Mínimos Quadrados Ordinários (MQO) para captar o efeito sobre a renda per capita quando há APL apoiado. Em um segundo momento, buscou-se o efeito fixo ao longo do tempo para os municípios com APL apoiado. Nessa etapa, usou-se o modelo de diferença-em-diferença. $\mathrm{O}$ período de análise compreende os anos de 1980, 1996, 2000, 2007, 2010.

\section{RESULTADOS}

Os resultados obtidos pelo modelo de MQO e de Diferença-em-Diferença são apresentados na tabela 2. Nessa tabela são apresentados os resultados obtidos na regressão considerando os 33 APLs apoiados como existentes desde o ano de 2000. Como dito anteriormente, o estimador por MQO possui um forte viés. O estimador por MQO identifica uma correlação entre o aumento na renda per capita do município e o fato do município ter um APL apoiado. No entanto sabe-se que essa correlação não é sinônimo de causalidade. 
O sinal positivo e significativo obtido no modelo por MQO pode ser um indicativo de que o estimador está superestimando o efeito do APL, que pode ser explicado pelo efeito das variáveis não ob- serváveis, tais como: diferenças no padrão tecnológico, na forma de lidar com a terra, nas habilidades administrativas e políticas que estão presentes de forma heterogênea entre os municípios, resultando nesse viés.

Tabela 2 - Comparativo da estimativa MQO e Diferença-em-Diferença (Dif-Dif)

\begin{tabular}{|c|c|c|}
\hline \multirow{3}{*}{ APL } & MQO & Dif-Dif \\
\hline & $0,122^{* * *}$ & $-0,027$ \\
\hline & $(0,022)$ & $(0,032)$ \\
\hline \multirow[t]{2}{*}{$a n o=1996$} & $-0,072^{* *}$ & $-0,035$ \\
\hline & $(0,035)$ & $(0,024)$ \\
\hline \multirow[t]{2}{*}{ ano $=2000$} & $-0,027$ & $0,133^{* * *}$ \\
\hline & $(0,036)$ & $(0,033)$ \\
\hline \multirow[t]{2}{*}{$a n o=2007$} & $0,263^{* * *}$ & $0,412^{* * *}$ \\
\hline & $(0,037)$ & $(0,035)$ \\
\hline \multirow[t]{2}{*}{ ano $=2010$} & $0,352^{* * *}$ & $0,501^{* * *}$ \\
\hline & $(0,037)$ & $(0,034)$ \\
\hline \multirow[t]{2}{*}{ _cons } & $1,635^{* * *}$ & $1,601^{* * *}$ \\
\hline & $(0,028)$ & $(0,021)$ \\
\hline R2 & 0,211 & 0,543 \\
\hline Número de observações & 2.118 & 2.118 \\
\hline $\begin{array}{l}\text { nota: }{ }^{* * *} \mathrm{p}<0.01,{ }^{* *} \mathrm{p}<0.05,{ }^{*} \mathrm{p}<0.1 \\
\text { Entre parênteses erro-padrão }\end{array}$ & & \\
\hline
\end{tabular}

Ao aplicar-se o método de correção de viés por meio da busca do efeito causal da presença de um APL na renda do município, o efeito apresentado no modelo de MQO desaparece. O sinal do estimador é negativo, porém sem significância estatística. Tal resultado sugere que a política de apoio aos APLs não surtiu efeito sobre o crescimento da renda per capita dos municípios gaúchos.

Porém, como se pode estar correndo um erro ao indicar que todos os 33 APLs já recebiam apoio no ano de 2000, em um segundo modelo aplica-se o mesmo modelo econométrico de Diferença-emDiferença para uma sub-amostra dos APLs. Agora, foram utilizados apenas os
APLs que se sabe que já existiam em 2000 e que recebem o apoio de forma contínua desde o seu início. Esses APLs são os que a literatura descreve como os mais consolidados, estruturados e com apoio contínuo do governo. Portanto, se o efeito da política pública em apoiar um APL surte efeitos mais de longo prazo, então tais APLs devem registrar a causalidade da política pública sobre a suas dinâmicas econômicas. Para essa sub-amostra foram considerados os seguintes APLs: APL metalmecânico, APL vitivinicultura, APL de máquinas e implementos agrícolas e APL moveleiro. A tabela 3 apresenta os resultados obtidos. 
Tabela 3 - Resultados das estimações separadas por tipologia de APL

\begin{tabular}{cccccc}
\hline Tipo Apl & Coef & $\begin{array}{c}\text { Robust } \\
\text { Std. Dev }\end{array}$ & $\mathbf{t}$ & $\mathbf{p}>(\mathbf{t})$ & $\{$ 95\% conf. Interval $\}$ \\
Metalmecânico & .0058068 & .0580943 & 0.10 & 0.920 & $-.108335 ; .1199485$ \\
cconst & 1.601304 & .0211972 & 75.54 & 0.000 & $1.559656 ; 1.642952$ \\
Vitivinicultura & -.0275179 & .0555375 & $-0,50$ & 0.620 & $-.1366361 ; .0816004$ \\
const & 1.601131 & 0.211912 & 75.56 & 0.000 & $1.559495 ; 1.642767$ \\
Moveleiro & -0.454579 & .0351501 & -1.29 & 0.197 & $-.1145197 ; .0236039$ \\
const & 1.60102 & .0211773 & 75.60 & 0.000 & $.1 .559412 ; 1.642629$ \\
Maq. e Implem. Agrícola & 0.1017549 & 0.0382851 & 2.66 & 0.008 & $0.265335 ; .1769763$ \\
Const & 1.603321 & 0.021151 & 75.80 & 0.000 & 1.5617641 .644878 \\
\hline
\end{tabular}

Os APLs vitivinicultura, metalmecânico e moveleiro não apresentam impacto no PIB per capita dos municípios onde eles estão presentes, suas estatísticas são não significativas. No entanto, o APL de Máquinas e Implementos Agrícolas apresentou um efeito de que a presença do APL apoiado aumentou a renda per capita em 0.10 pontos percentuais do que a média obtida pelos municípios que não tinham APL apoiado.

O Instituto Paranaense de Desenvolvimento Econômico e Social et al. (IPARDES et al., 2006) analisam o APL de máquinas e implementos agrícolas no Estado do Paraná e concluíram ser esta aglomeração relativamente intensiva em tecnologia e produtos de maior valor agregado, porém oportunizando a ampliação para a geração de renda e do emprego de maior qualificação, sendo um vetor de diversificação da base produtiva local. Esse fator explica parte dessa significância estatística para a realidade gaúcha ora pesquisada.

Vian et al. (2013), por sua vez, preencheram uma lacuna de estudos para o setor caracterizando-o de forma a melhor compreender sua estrutura, estratégias e desempenho. De maneira geral, esse segmento é concentrado em escala mundial e dinamizado por inovações tecnológicas.

Porém, como destaca o trabalho de Vian et al. (2013), a relação com o cliente se dá pela fidelização à marca, pela presença de uma rede de representantes das marcas próximo a eles e a estratégias agressivas de vendas. Então, pode-se supor que as variáveis não observadas que motivaram o resultado positivo do APL máquinas e implementos agrícolas estão mais associadas às características da indústria do setor do que aos incentivos do governo aos arranjos produtivos.

\section{CONSIDERAÇÕES FINAIS}

Nas últimas décadas, tem crescido o debate político sobre o apoio a arranjos produtivos locais como instrumento de política pública de promoção ao desenvolvimento regional. Apesar do avanço político desse instrumento, pouco ainda se tem de avaliação de seu impacto sobre o desempenho econômico. Este artigo objetivou contribuir para essa literatura oferecendo uma tentativa de avaliação do efeito causal do apoio aos APLs na renda per capita municipal.

Os resultados obtidos não permitem afirmar que os incentivos públicos têm impacto positivo sobre o PIB per capita dos municípios que têm APL. Apenas o caso do APL de máquinas e implementos agrícolas apresentou impacto positivo. É possível que características muito próprias desse setor expliquem o efeito. Com efeito, esse APL trabalha com uma gama de produtos de amplitude mercadológica, que tem sido comercializada no mercado nacional, regional, local e também no mercado externo. Destarte, há forte junção a montante e a jusante nesse APL (principais insumos e matérias-primas utilizados: aço, alumínio, ferro, pneu, mangueiras, tinta, rolamento, plástico, cimento, areia, pedra 
e telhas; principais serviços demandados: transporte, solda, comercialização etc.). Ademais, trata-se de um segmento que mobiliza governos e instituições com ações concretas e necessárias para o seu desenvolvimento, visto tratar especificamente de um segmento estratégico para a economia brasileira, o agronegócio, com responsabilidade nas questões da segurança alimentar e, também, agroenergética, sendo responsável por 37\% dos empregos e 22,15\% do PIB em 2012.

Para melhor avaliar a política pública de incentivo aos APLs, este artigo abordou o seu impacto em termos municipais. É possível que o impacto da política de apoio aos APLs esteja não no nível municipal, mas no nível da firma. Tal fato pode ser um limitante do presente trabalho, por isto se postula que novos trabalhos possam avaliar o impacto sobre a renda e emprego utilizando microdados setoriais, contribuindo para a presente discussão e debate. Da mesma forma, sabe-se que o efeito da política de apoio aos APLs pode não estar restrito à renda. Aspectos relacionados com o aprendizado, dinâmica competitiva, também são relevantes no apoio aos APLs. No entanto, para este trabalho, dispomos apenas da variável relacionada com a renda. Novos trabalhos podem ampliar a análise de avaliação da política pública para outros aspectos que vão além da renda.

\section{REFERÊNCIAS}

AMARAL FILHO, J. do. Sistemas e Arranjos Produtivos Locais. Planejamento e Políticas Públicas, n. 36, p. 171-212, jan./jun. 2011.

BANCO CENTRAL DO BRASIL (BCB). Estrutura Produtiva e Desempenho Recente da Economia Gaúcha. Boletim Regional do Banco Central do Brasil, julho 2011.

BANCO NACIONAL DE DESENVOLVIMENTO ECONÔMICO E SOCIAL (BNDES). Arranjos produtivos locais e desenvolvimento regional. Análise do mapeamento e das políticas para Arranjos Produtivos Locais no Brasil. Seminários, outubro de 2004.
BOURLEGAT, Cleonice Alexandre Le. Princípios de organização e desempenho de um modelo econômico agroindustrial emergente no centro-oeste: o caso do arranjo produtivo local da fécula de mandioca. In: LASTRES, Helena M. M.; CASSIOLATO, José E. (Org.). Estratégias para o desenvolvimento: um enfoque sobre arranjos produtivos locais do Norte, Nordeste e Centro-oeste brasileiros. Rio de Janeiro: E-papers, 2006.

BRITTO, J.; STALLIVIERI, F. Inovação, cooperação e aprendizado no setor de software no Brasil: análise exploratória baseada no conceito de Arranjos Produtivos Locais (APLs). Economia e Sociedade, Campinas, SP, v. 19, n. 2 (39), p. 315-358, ago. 2010.

CARVALHO, F. D.; SANTANA, A. C. de; MENDES, F. A. T. Análise de Cluster da indústria de móveis de madeira do Pará. Novos Cadernos do NAEA, v. 9, n. 2, dez. 2006.

CHATTERJI, A.; GLAESER, E. L.; KERR, W. R. Clusters of entrepreneurship and innovation. National Bureau of Economic Research, Working Paper n. 19013, 2013.

COSTA, O. de M. E. da. Arranjos Produtivos Locais. APL's como estratégia de desenvolvimento: uma abordagem teórica. Fortaleza: Instituto de Pesquisa e Estratégia Econômica do Ceará (IPECE), 2011.

COSTA, F. de A.; ANDRADE, W. D. C. de; SILVA, F. C. F. da. O arranjo produtivo de frutas na região polarizada por Belém do Pará. In: LASTRES, H. M. M.; CASSIOLATO, J. E. (Org.). Estratégias para o desenvolvimento: um enfoque sobre arranjos produtivos locais do Norte, Nordeste e Centro-oeste brasileiros. Rio de Janeiro: E-papers, 2006. 288p.

DELGADO, M.; PORTER, E. M.; STERN, S. Clusters, convergence, and economic performance. National Bureau of Economic Research, Working Paper n. 18250, 2012.

DIAS, N. C. Arranjos produtivos locais como estratégia de desenvolvimento. Desenvolvimento em Questão, Ijuí, RS, ano 9, n. 17, jan./jun. 2011.

FALCK, O.;HEBLICH, S.; KIPAR, S. Industrial innovation: direct evidence from a clusteroriented policy. Regional Science and Urban Economics, n. 40, p. 574-582, 2010. 
FUNDAÇÃO INSTITUTO POLO AVANÇADO DE SAÚDE (FIPASE). APL EMHO - Equipamentos Médicos, Hospitalares e Odontológicos. [s/d]. Disponível em: <http:// fipase.com. br/>. Acesso em: 18 nov. 2013.

HASHINO, T.; OTSUKA, K. Cluster-based industrial development in contemporary developing countries and modern Japanese economic history. Journal of The Japanese and International Economies, n. 30, p. 19-32, 2013.

INSTITUTO PARANAENSE DE DESENVOLVIMENTO ECONÔMICO E SOCIAL (IPARDES); UNIVERSIDADE ESTADUAL DO OESTE DO PARANÁ (UNIOESTE); SECRETARIA DE ESTADO DO PLANEJAMENTO E COORDENAÇÃO GERAL. APL de produção de máquinas e equipamentos para a agricultura, avicultura e obtenção de produtos animais: estudo de caso. Curitiba: IPARDES, 2006. 36p.

KIRSCHBAUM, C.; CARVALHO, L. F. N.; BRITO, L. A. L.; BINDER, M. P.; VASCONCELOS, F. C. de. Os desafios do cluster vitivinícola da serra gaúcha. In: SERIO, L. C. Di (Org.). Clusters empresariais no Brasil: casos selecionados. São Paulo: Saraiva, 2007.

MARTIN, P; MAYER, T; MAYNERIS, F. Public support to clusters: a firm level study of French "Local Productive Systems". Regional Science and Urban Economics, n. 41, p. 108-123, 2011.

MINISTÉRIO DODESENVOLVIMENTO, INDÚSTRIA E COMÉRCIO EXTERIOR (MDIC). Arranjos Produtivos Locais. 2000. Disponível em: <http:/ / www.mdic.gov.br//sitio/interna/interna.php?area $=2 \& m e n u=300>$. Acesso em: 6 nov. 2013.

NISHIMURA, J.; OKAMURO, H. Subsidy and networking: the effects of direct and indirect support programs of the cluster policy. Research Policy, n. 41, p. 714-727, 2011.

NORONHA, E.; TURCHI, L. Política industrial e ambiente institucional na análise de arranjos produtivos locais. Texto para discussão 1076. Brasília: IPEA, 2005.

POSSAS, M. L. Concorrência schumpeteriana. In: KUPFER, David; HASENCLEVER, Lia (Org.). Economia industrial: fundamentos teóricos e práticos no Brasil. Rio de Janeiro: Campus, 2002.
Concorrência e competitividade: notas sobre estratégia e dinâmica seletiva na economia capitalista. São Paulo: Hucitet, 1999.

RIBEIRO, K. A.; NASCIMENTO, D. C.; CASSUNDE JUNIOR, N. F.; MORATO, J. A. Q. Arranjo produtivo local (APL) como estratégia de potencializar as fronteiras mercadológicas do apicultor no perímetro de irrigação Senador Nilo Coelho em PetrolinaPE. Revista Gestão, Finanças e Contabilidade, v. 3, n. 2, maio/ago. 2013.

RIO GRANDE DO SUL [Governo do Estado do]. Assembleia Legislativa. Decreton. 48.936 de 20 de março de 2012. Sistema Legis. Disponível em: <http://www.al.rs.gov.br/legislativo/ Legisla\%C3\% A7\% C3\% A3oEstadual.aspx>. Acesso em: 11 nov. 2013.

. Assembleia Legislativa. Lein.13.839 de5 dedezembrode2011.SistemaLegis. Disponível em: <http://www.al.rs.gov.br/legislativo/ Legisla\%C3\% A7\%C3\% A3oEstadual.aspx>. Acesso em: 11 nov. 2013.

SCHERER, F.; ROSS, D. Industrial market structure and economic performance. Boston: Houghton Mifflin, 1990.

SECRETARIA DE DESENVOLVIMENTO E PROMOÇÃO DO INVESTIMENTO DO RIO GRANDE DOSUL (SDPI). Plano de Implantação da Política Industrial: Desenvolvimento Econômico do RS. 2013. Disponível em: $<$ http://www.sdpi.rs.gov.br/>. Acesso em: 12 nov. 2013.

SERVIÇO BRASILEIRO DE APOIO ÀS MICROEPEQUENASEMPRESAS (SEBRAE). Cara brasileira: a brasilidade nos negócios - um caminho para o made in Brazil. Brasília: Sebrae Nacional, 2002.

SUZIGAN, W.; FURTADO, J.; GARCIA, R.; SAMPAIO, S. Clusters ou Sistemas Locais de Produção: mapeamento, tipologia e sugestões de políticas. Revista de Economia Política, v. 24, n. 2, out./dez. 2004.

TATSCH, A. L.; PASSOS, M. C. Políticas para promoção de arranjos produtivos e inovativos locais no Rio Grande do Sul: os casos dos arranjos de máquinas e implementos agrícolas e de móveis. In: CASSIOLATO, J. E.; LASTRES, H. M. M.; STALLIVIERI, F. (Org.). Arranjos produtivos locais: uma alternativa para o desenvolvimento. Rio de Janeiro: E-papers, 2008. (Volume 2: Experiência de política). 
TIROLE, J. The theory of industrial organization. Cambridge (Mass): MIT Press, 1988.

VIAN, C. E. de F.; ANDRADE JÚNIOR, A. M.; BARICELO, L. G.; SILVA, R. P. Origens, evolução e tendências da indústria de máquinas agrícolas. Revista de Economia e Sociologia Rural, Piracicaba, SP, v. 51, n. 4, p. 719-744, out./dez. 2013.
WOOLDRIDGE, J. Introdução à Econometria: uma abordagem moderna. São Paulo: Cengage Learning, 2006.

ZANIN, V.; COSTA, R. M. da; FEIX, R. D. As aglomerações industriais do Rio Grande do Sul: identificação e seleção. Estudo de Aglomerações Industriais e Agroindustriais no RS. Porto Alegre: FEE, 2013.

\section{Sobre os autores:}

Diogo Sá Carvalho: Mestre em Economia Aplicada (PPGOM/UFPel). Professor da Faculdade de Tecnologia de São Paulo (Fatec Senac), Pelotas, RS. E-mail: diogocarvalhodsc@gmail.com

André Carraro: Pós-Doutor em Economia (FGV-SP, 2012). Doutor em Economia (PPGE/ UFRGS, 2003). Professor no Departamento de Economia da Universidade Federal de Pelotas, RS. E-mail: andre.carraro@gmail.com

Pery Francisco Shikida: Pós-Doutor em Economia (FGV-SP, 2010), Doutor em Economia Aplicada (ESALQ-USP, 1997), Mestre em Economia Agrária (ESALQ-USP, 1992), Economista (UFMG, 1989). Universidade Estadual do Oeste do Paraná (UNIOESTE), Toledo, PR. E-mail: peryshikida@hotmail.com 